\title{
Appendix Large Cell Neuroendocrine Carcinoma
}

National Cancer Institute

\section{Source}

National Cancer Institute. Appendix Large Cell Neuroendocrine Carcinoma. NCI

Thesaurus. Code C96426.

An aggressive, high-grade and poorly differentiated carcinoma with neuroendocrine

differentiation that arises from the appendix. It is characterized by the presence of malignant large cells. 